\title{
MECHANICAL BUCKLING OF FUNCTIONALLY GRADED POLYETHYLENE/CLAY NANOCOMPOSITES COLUMNS BASED ON THE ENGESSER-TIMOSHENKO BEAM THEORY
}

\author{
Mohhamad Hossein Yas, Mahdi Karami Khorramabadi \\ Department of Mechanical Engineering, Razi University, Kermanshah, Iran \\ e-mail:yas@razi.ac.ir; mehdi_karami2001@yahoo.com
}

\begin{abstract}
This paper deals with mechanical buckling of polyethylene/clay nanocomposite beams of functionally graded and uniformly distributed of nanoclay subjected to axial compressive load with simply supported conditions at both ends. The Young moduli of functionally graded and uniformly distributed nanocomposites are calculated using a genetic algorithm procedure and then compared with experimental results. The formulation is modified to include the effect of nanoparticles weight fractions in the calculation of the Young modulus for uniform distribution. Also, it is modified to take into account the Young modulus as a function of the thickness coordinate. The displacement field of the beam is assumed based on the Engesser-Timoshenko beam theory. Applying the Hamilton principle, governing equations are derived. The influence of nanoparticles on the buckling load of the beam is presented. To investigate the accuracy of the present analysis, a compression study with the experimental results is carried out.
\end{abstract}

Keywords: mechanical buckling, functionally graded nanocomposite, montmorillonite, genetic algorithm theory

\section{Introduction}

Nanomaterials have aroused interest among scientific communities in the field of physics, chemistry and engineering. Some of these materials are nanoparticles, nanowires and nanotubes (Jia et al., 2014; Nam et al., 2001; Lei et al., 2013; Pakdaman et al., 2013; Grigoriadi et al., 2014). Compared to experimental studies, the number of publications dealing with theoretical prediction of properties in polymer/clay nanocomposites is relatively small. Fornes and Paul (2003) applied the Halpin-Tsai and Mori-Tanaka reinforcement theories to predict the modulus of nylon based nanocomposites. The modulus obtained using Mori-Tanaka calculation increased with nanoclay reinforcement as predicted. The Halpin-Tsai formula gave higher values to the modulus but could still be used to predict its value.

Some efforts have been focused on the modeling of mechanical properties of nanoclay-reinforced polymer composites (Sheng et al., 2004) and nanoparticle-reinforced polymer composites (Smith et al., 2002; Brown et al., 2003). These modeling efforts have demonstrated the need for the development of a model that would predict mechanical properties of nanoparticle/polyimide composites as a function of the nanoparticle size and weight fraction as well as the molecular structure of the nanoparticle/polyimide interface. Genetic algorithms (GA) are a family of computational models inspired by evolution. These algorithms encode a potential solution or a specific problem on a simple chromosome-like data structure and apply recombination operators to these structures so as to preserve critical information. Structural stability is considered to be the one of the most important engineering issues in the design and application of slender structures. Buckling and post-buckling behaviour are the two main types of structural instability, they often govern failure of structures under static or dynamic compressive loading 
conditions, thus, have been investigated by several researchers in the past decades. Vodenitcharova and Zhang (2006) presented analyses of pure bending and bending-induced local buckling of a nanocomposite beam based on a continuum mechanical model and found that single-walled carbon nanotube (SWCNT) buckled at smaller bending angles and greater flattening ratios in thicker matrix layers. Based on the classical laminated plate theory and third-order shear deformation theory, Arani et al. (2011) analytically and numerically studied buckling behaviour of laminated composite plates. The optimal orientation of CNTs to achieve the highest critical load and corresponding mode shape were calculated for different kinds of boundary conditions as well as aspect ratios of the plates. Shen (2011) presented a postbuckling analysis of cylindrical shells reinforced by SWCNTs subjected to axial compression and lateral or hydrostatic pressure in thermal environments. The results revealed that the mid-plane symmetric functionally graded distribution of reinforcements could increase the buckling load as well as postbuckling strength of the shells and confirmed that the postbuckling equilibrium path for both FG- and UD-CNTRC cylindrical shells under axial compression was unstable. Mosallaie Barzoki et al. (2012) analyzed the torsional buckling of electro-thermo-mechanical cylindrical shells reinforced by polymer piezoelectric double-walled boron nitride nanotubes. They expressed properties of the electro-thermo-mechanical smart composite materials using a micro-mechanical approach. Their results stated that the buckling load increased with increaseing the foam core. Eltaher et al. (2013) illustrated the size dependent effect on static and buckling behaviour of an FG nano-beam based on the nonlocal elasticity theory. They used the finite element method to discretize this model and obtained a numerical approximation for equilibrium equations. Yin et al. (2015) studied static bending and buckling of an FGPR nanoscale beam based on the nonlocal Timoshenko beam model. The results revealed that the deflections of the FGPR beam increased with the nonlocal parameters, and the buckling loads decreased with it. Li et al. (2015) investigated the relationship between the critical buckling loads of the functionally graded material (FGM) Levinson beams (LBs) and those of the corresponding homogeneous Euler-Bernoulli beams (HEBBs). Barati et al. (2014) studied buckling of functionally graded beams with imperfectly integrated surface piezoelectric layers under low velocity and found that the piezoelectric actuators induced tensile piezoelectric force produced by applying negative voltages that significantly affected the stability of the functionally graded Engesser-Timoshenko beam with piezoelectric actuators. Heydari (2011) presented a new analytical method for buckling analysis of rectangular and annular beams made up of functionally graded materials with constant thickness and Poisson's ratio. The results revealed that dimensionless first mode shape of buckling for prismatic functionally graded beams was similar to prismatic homogeneous beams. Simsek and Yurtsu (2013) studied static bending and buckling of a functionally graded (FG) nanobeam based on the nonlocal Timoshenko and Euler-Bernoulli beam theory. The results showed that the new nonlocal beam model produced larger deflection and smaller buckling load than the classical (local) beam model. Rychlewska (2014) presented the critical buckling loads for axially functionally graded (FG) beams subjected to a distributed axial load and found that the critical buckling loads of a homogeneous beam calculated by the proposed approach were in good agreement with those available in literature. Houari et al. (2013) investigated the size-dependent buckling behaviour of functionally graded (FG) nanobeams on the basis of the nonlocal continuum model. The effects of the nonlocal parameter, aspect ratio, various material compositions on the stability responses of the FG nanobeams were discussed. Ghiasian et al. (2015) studied nonlinear thermal dynamic buckling of FGM beams and found that for beams with stable post-buckling equilibrium path, no dynamic buckling occurred according to the Budiansky-Roth criterion. Sun et al. (2016) investigated thermal buckling and post-buckling of FGM Timoshenko beams on a nonlinear elastic foundation. The results revealed that post-buckling behaviour of a FGM Timoshenko beam exhibited bifurcations under both uniform and non-uniform temperature rise. Kiani and Eslami (2010) studied buckling of beams made of functionally graded materials under various types of 
thermal loading. The formulations were compared using reduction of results for the functionally graded beams to those of isotropic homogeneous beams given in the literature. Kiani and Eslami (2013) investigated buckling of beams made of functionally graded materials (FGM) under thermomechanical loading. The results revealed that in each case of thermal loading, the Timoshenko beam theory predicted lower values for critical buckling temperature in comparison with the Euler beam theory. Majumdar and Das (2016) determined thermal buckling loads of various functionally graded material beams with both ends clamped. The effect of the limit thermal load at which the effective elastic modulus and/or thermal expansion coefficient become theoretically zero was considered. Rafiee et al. (2009) experimentally investigated buckling of graphene/epoxy nanocomposite beam structures. They revealed that graphene nanocomposites showed potential to provide significant enhancement in buckling stability, which is an important consideration for the design of ultra light-weight and highly optimized structural elements used in aerospace applications.

The present work deals with mechanical buckling of polyethylene/clay nanocomposite beams with functionally graded (FG) and uniformly distributed nanoclay. The beams are subjected to axial compressive load and are simply supported at both ends. By using a genetic algorithm procedure, Young's modulus of functionally graded and uniformly distributed nanocomposites is calculated and then compared with experimental data. The displacement field of the beam is assumed based on the Engesser-Timoshenko beam theory. Applying the Hamilton principle, the governing equations are derived. The influence of nanoparticles on the buckling load of the beam is presented. To investigate the accuracy of the present analysis, a compression study is carried out with the experimental results.

\section{Experimental data}

\subsection{Materials}

The polymer matrix used in this study was a linear low-density polyethylene (LDPE) with the trade name LL209AA from Arak Petrochemical Co. (Iran), with the melt flow index (MFI) of $1.5 \cdot 10^{-6} \mathrm{~kg} / \mathrm{s}$ and density of $\rho=920 \mathrm{~kg} / \mathrm{m}^{3}$. The nanofiller was $\mathrm{K} 10$ modified montmorillonite (MMT) from Sigma-Aldrich, Germany. Also, the polyethylenglycol which has been used in this study was polyethylenglycol 40 from Merk-KGaA, Germany.

\subsection{Mechanical properties}

The tensile properties were evaluated according to ASTM D638 using dumbbell-shaped samples and a Gotech universal testing machine (Model GT-AI5000L), a tensile tester with a crosshead speed of $8.33 \cdot 10^{-4} \mathrm{~m} / \mathrm{s}$. The material compositions of the nanocomposites are listed in Table 1. In this table, wt. is considered as the weight percent.

Table 1. Sample compositions

\begin{tabular}{|c|c|c|c|}
\hline Sample & $\begin{array}{c}\text { LDPE } \\
\text { [wt.\%] }\end{array}$ & $\begin{array}{c}\text { Compatibilizer } \\
\text { [wt.\%] }\end{array}$ & $\begin{array}{c}\text { MMT } \\
\text { [wt.\%] }\end{array}$ \\
\hline \hline 1 & 85 & 15 & - \\
\hline 2 & 82 & 15 & 3 \\
\hline 3 & 80 & 15 & 5 \\
\hline 4 & 78 & 15 & 7 \\
\hline
\end{tabular}

The effect of nanoparticles with different weight fractions on the elastic modulus is shown in Fig. 1. 


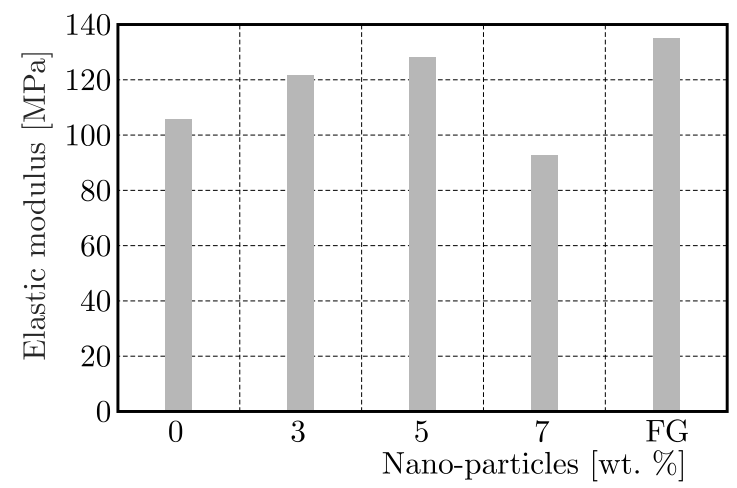

Fig. 1. The effect of nanoparticles with different weight fractions on the elastic modulus

As noticed, the elastic modulus begins to increase up to 5 wt.\% of nanoclay. As the clay weight fraction exceeds 5 wt.\%, the elastic modulus levels off, but for the functionally graded distribution, the elastic modulus is generally larger than the corresponding values for the uniform distribution of nanoclay. In fact, the elastic modulus of the functionally graded sample is the total result of the tensile test. The elastic moduli of all samples are calculated by using the machine software. Figure 2 illustrates the effect of nanoparticles with different weight fractions on the yield strength.

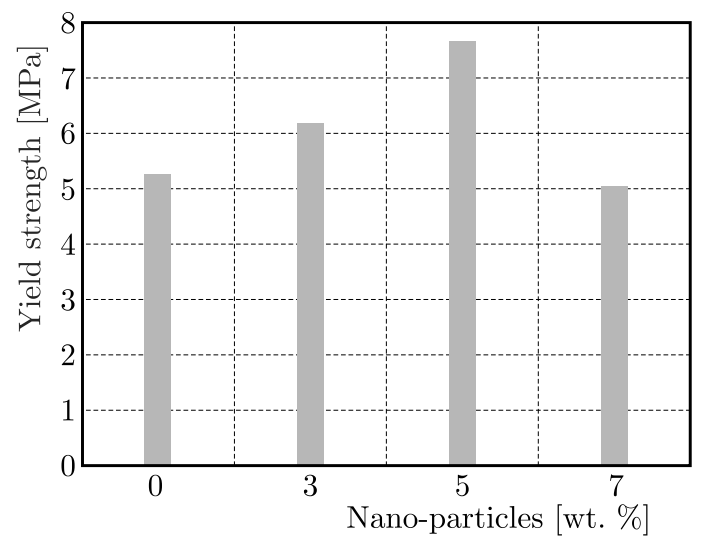

Fig. 2. The effect of nanoparticles with different weight fractions on the yield strength

As observed, the yield strength begins to increase up to $5 \mathrm{wt} . \%$ of nanoclay. As the weight fraction of nanoclay exceeds $5 \mathrm{wt} . \%$, the yield strength levels off.

\subsection{Buckling tests}

We used a beam apparatus from TQ, England (Model SM1005) to study mechanical buckling of columns made of functionally graded and uniformly distributed nanocomposites. The test specimens have a rectangular cross section $0.02 \mathrm{~m} \times 0.004 \mathrm{~m}$ and length of $0.2 \mathrm{~m}$ with both ends simply supported.

\section{Modeling}

\subsection{Genetic Algorithm}

The GA is an unorthodox search or optimization algorithm, which was first suggested by Holland (1975). As the name suggests, the GA was inspired by the processes observed in natural evolution. It attempts to mimic these processes and utilizes them for solving a wide range of 
optimization problems. In general, GA performs directed random searches through a given set of criteria. These criteria are required to be expressed in terms of an objective function, which is usually referred to as a fitness function. The GA method requires that the set of alternatives to be searched be finite. To apply them to an optimization problem where this requirement is not met, the set involved must be discretized and appropriate finite subset must be selected. It is further required that the alternatives be coded in chromosomes of some specific finite length which consists of symbols from some finite alphabet. These are called chromosomes; the symbols that form them are called genes, and their set is called a gene pool. The GA method searches for the best alternative (in the sense of a given fitness function) through chromosome evolution. The basic steps in the GA are shown in Fig. 3.

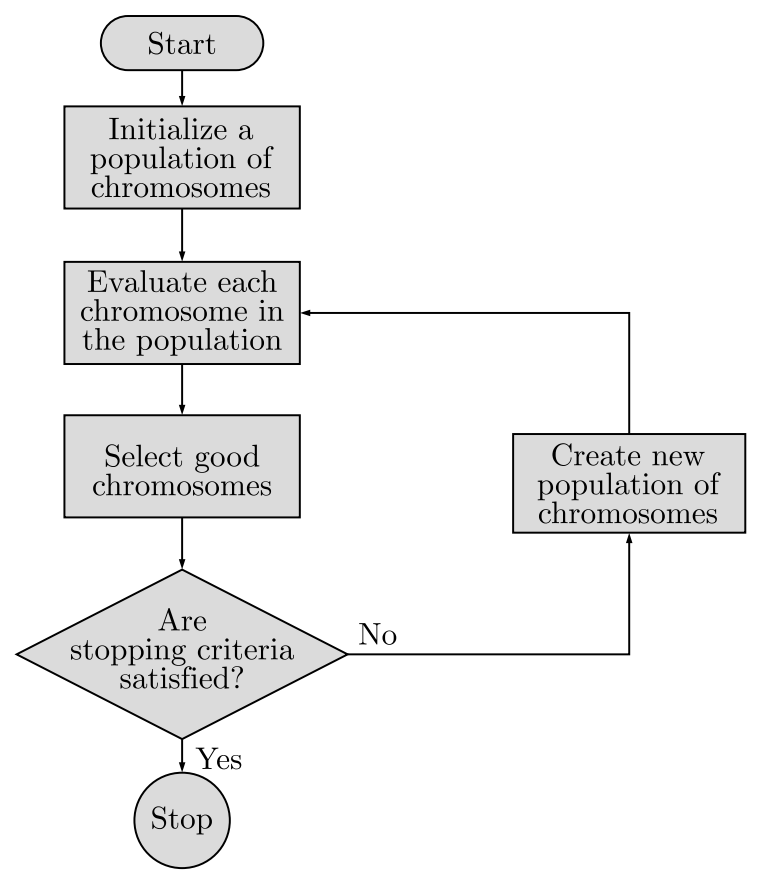

Fig. 3. High level description of the GA

First, the initial population of chromosomes is randomly selected. Then each chromosome in the population is evaluated in terms of its fitness (expressed by the fitness function). Next, a new population of chromosomes is selected from the given population by giving a greater chance to select chromosomes with higher fitness. This is called the reproduction operation. The new population may contain duplicates. If given stopping criteria (e.g., no chance in the old and new population, specified computing time, etc.) are not met, some specific, genetic-like operations are performed on chromosomes of the new population. These operations produce new chromosomes, called offsprings $s$. The same steps of this process, evaluation and reproduction operations are then applied to chromosomes of the resulting population. The whole process is repeated until the given stopping criteria are met. The solution is expressed by the best chromosome in the final population.

\subsection{Theoretical predictions}

First, it is assumed that the material properties can be described by a simple polynomial depending on the nanoclay weight percentage. The coefficients of this polynomial function are found by maximizing the accuracy. The $1-R_{a d j}^{2}$ is introduced as the fitness function which is to be minimized. $R_{a d j}^{2}$ is the accuracy criterion of an arbitrary mechanical property function (such as Young's modulus). $R_{a d j}^{2}$ is defined as a process which is demonstrated below. The mechanical 
property is a function of the nanoclay weight percent and $R_{a d j}^{2}$ is a function of coefficients which are introduced below. $M_{i}$ and $W$ are considered as the mechanical properties and the nanoclay weight percent, respectively. $M_{i}$ is expressed as a polynomial function of $W$ as follows

$$
M_{i}=\sum_{j=0}^{4} a_{j i} W^{j}
$$

Now, the coefficients $a_{j i}$ are found by maximizing the accuracy of the polynomial function. The equations can be written as

$$
R_{a d j}^{2}=1-\frac{V A R_{E}}{V A R_{T}}
$$

in which

$$
\begin{array}{ll}
V A R_{E}=\frac{S S_{E r r}}{n-k-1} & V A R_{T}=\frac{S S_{T o t}}{n-1} \\
S S_{T o t}=\sum_{i=1}^{n}\left(y_{i}-\bar{y}\right)^{2} & S S_{E r r}=\sum_{i=1}^{n}\left(y_{i}-M_{i}\right)^{2} \\
\bar{y}=\frac{1}{n} \sum_{i=1}^{n} y_{i} & M_{i}(W)=a_{0 i}+a_{1 i} W+a_{2 i} W^{2}+a_{3 i} W^{3}
\end{array}
$$

In these equations, $n=4$ is the number of experiments, $k=0$ is the number of duplicated experiments and $y_{i}$ denotes the experimentally measured mechanical properties. $a_{j i}$ coefficients are obtained after approximately 40 generations by minimization of $1-R_{a d j}^{2}$ through using MATLAB. Obtaining the $a_{j i}$ coefficients, the Young modulus of the uniformed distribution can be expressed as a function of the nanoclay weight percent as follows

$$
E=-3.401 W+4.97 W^{2}-0.677 W^{3}+105.338
$$

Here, $W$ is the nanoclay weight percent (wt. $\%$ and $W$ have the same value, e.g., wt. $\%=W=3$ ). To validate the presented results, comparison studies are carried out for the Young modulus of the uniformly distributed nanocomposites as presented in Table 2 .

Table 2. Comparison of Young's modulus for uniformly distributed nanocomposites

\begin{tabular}{|c|c|c|}
\hline $\begin{array}{c}\text { Nanoclay } \\
\text { weight } \\
\text { percent }\end{array}$ & $\begin{array}{c}\text { Theoretical } \\
\text { predictions } \\
{[\mathrm{MPa}]}\end{array}$ & $\begin{array}{c}\text { Experimental } \\
\text { results } \\
{[\mathrm{MPa}]}\end{array}$ \\
\hline \hline pure & 105.338 & 105.338 \\
\hline $3 \%$ & 121.586 & 121.582 \\
\hline $5 \%$ & 127.958 & 127.939 \\
\hline $7 \%$ & 92.85 & 92.795 \\
\hline
\end{tabular}

The compression between theoretical predictions and the experimental data shows high accuracy of the present analysis. Equation (3.4) can also be used to derive a suitable relation for Young's modulus of the functionally graded distribution. The specimen with functionally graded distribution consists of four perfectly bonded sheets with a total thickness of $4 \mathrm{~mm}$. Each sheet has $1 \mathrm{~mm}$ in thickness with different nanoparticles weight fractions (pure, $1 \mathrm{wt} . \%, 3 \mathrm{wt} . \%$ and 5 wt.\%). The Young modulus can be written as

$$
E(z)= \begin{cases}-3.401(2 z+\operatorname{sgn}(z))+4.97(2 z+\operatorname{sgn}(z))^{2} & \\ -0.677(2 z+\operatorname{sgn}(z))^{3}+105.338 & \text { for } \quad 0 \leqslant z<4 \\ 92.85 & \text { for } \quad z=4\end{cases}
$$


As mentioned before, the Young modulus is assumed to vary as a function of the thickness coordinate $z$. By using a simple change of the variable as $z=\bar{z}+2$, the coordinate $\bar{z}$ changes within $-2 \leqslant \bar{z} \leqslant 2$. Equation (3.5) can be verified via employing the buckling analysis of the functionally graded nanocomposite beam under axial compressive load.

\section{Formulation of the problems}

The formulation is presented based on the assumptions of the Engesser-Timoshenko beam theory. Based on this theory, the displacement field can be written as (Wang and Reddy, 2000)

$$
u(x, \bar{z})=\bar{z} \phi(x) \quad w(x, \bar{z})=w_{0}(x, \bar{z})
$$

In view of the displacement field given by Eqs. (4.1), the strain displacement relations are (Wang and Reddy, 2000)

$$
\varepsilon_{x x}=\frac{\partial u}{\partial x}=\bar{z} \frac{d \phi}{d x} \quad \gamma_{x z}=\frac{\partial u}{\partial \bar{z}}+\frac{\partial w}{\partial x}=\phi+\frac{d w}{d x}
$$

Consider a functionally graded beam under axial compressive load with a rectangular crosssection as shown in Fig. 4.

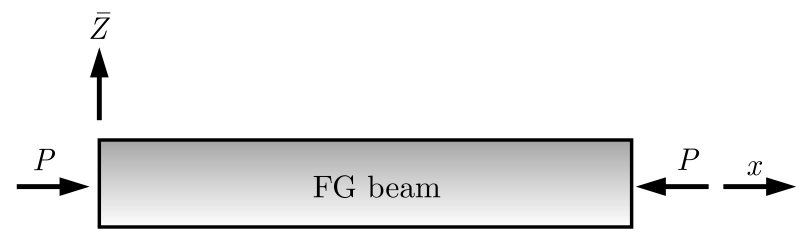

Fig. 4. Simply supported beam under compressive load

Thickness, length and width of the beam are denoted by $h, L$ and $b$, respectively. The $x y$-plane coincides with the midplane of the beam and the $\bar{z}$-axis located along the thickness direction. The Young modulus $E$ is assumed to vary as a function of the thickness coordinate variable $\bar{z}$ $(-2 \leqslant \bar{z} \leqslant 2)$. The constitutive relations for the functionally graded Engesser-Timoshenko beam are given by (Reddy, 2004)

$$
\sigma_{x x}=E(\bar{z}) \varepsilon_{x x} \quad \sigma_{x z}=G(\bar{z}) \gamma_{x z}
$$

where $\sigma_{x x}, \sigma_{x z}, E(\bar{z})$ and $G(\bar{z})$ are the normal stress, shear stress, the Young and shear modulus, respectively. The shear modulus can be written as (Thomas et al., 2013)

$$
G(\bar{z})=\frac{E(\bar{z})}{2(1+\nu)}
$$

where $\nu$ is the Poisson ratio, estimated with the aid of the relation (Kozlov et al., 2012)

$$
\frac{\sigma_{y}}{E}=\frac{1-2 \nu}{6(1+\nu)}
$$

where $\sigma_{y}$ is the yield strength and equals $6.645 \mathrm{MPa}$ from a tensile test. In fact, the total yield strength for the whole functionally graded sample can be obtained from the tensile test and calculated by using the machine software like the elastic modulus for the functionally graded sample. Also, the Poisson ratio assumed to be constant through thickness of the beam (Lei et al., 2013). So, equation (4.5) can be used to estimate the Poisson ratio for the whole sample. Also, $u$ and $w$ are the displacement components in the $x$ - and $\bar{z}$-directions, respectively. 
The potential energy can be expressed as (Wang and Reddy, 2000)

$$
U=\frac{1}{2} \int_{v}\left(\sigma_{x x} \varepsilon_{x x}+\sigma_{x z} \gamma_{x z}\right) d v
$$

Substituting Eq. (4.2) and Eq. (4.3) into Eq. (4.6) and neglecting higher-order terms, we obtain

$$
U=\frac{1}{2} \int_{v}\left\{\left[\left(E(\bar{z})\left(\bar{z} \frac{d \phi}{d x}\right)\right]\left(\bar{z} \frac{d \phi}{d x}\right)+\left[G(\bar{z})\left(\phi+\frac{d w}{d x}\right)\right]\left(\phi+\frac{d w}{d x}\right)\right\} d v\right.
$$

The width of the beam is assumed to be constant, which is obtained by integrating along $y$ over $v$. Then Eq. (4.7) becomes

$$
U=\frac{1}{2} \int_{0}^{L}\left\{D\left(\frac{d \phi}{d x}\right)^{2}+\frac{A}{2(1+\nu)}\left[\phi^{2}+\left(\frac{d w}{d x}\right)^{2}+2 \phi \frac{d w}{d x}\right]\right\} d x
$$

where

$$
A=b K_{s} \int_{-h / 2}^{+h / 2} G(\bar{z}) d z \quad D=b \int_{-h / 2}^{+h / 2} \bar{z}^{2} E(\bar{z}) d z
$$

where $A, D$ and $K_{s}$ are the shear rigidity, flexural rigidity and shear correction factor, respectively. The beam is subjected to the axial compressive load $P$ as shown in Fig. 4. The work done by the axial compressive load can be expressed as (Wang and Reddy, 2000)

$$
W=\frac{1}{2} \int_{0}^{L} P\left(\frac{\partial w}{\partial x}\right)^{2} d x
$$

We apply the Hamilton principle to derive the equilibrium equations of the beam as follows (Reddy, 2004)

$$
\int_{0}^{t}(T-U+W) d t=0
$$

where $T$ is kinetic energy. Substituting Eq. (4.8) and Eq. (4.10) into Eq. (4.11) leads to the following equilibrium equations of the functionally graded Engesser-Timoshenko beam

$$
(P-A) \frac{d^{2} w}{d x^{2}}-A \frac{d \phi}{d x}=0 \quad D \frac{d^{2} \phi}{d x}-A\left(\phi+\frac{d w}{d x}\right)=0
$$

\section{Stability analysis}

The boundary conditions for the simply supported Engesser-Timoshenko column are given by

$$
w=\frac{d^{2} w}{d x^{2}}=\frac{d \phi}{d x} \quad x=0, L
$$

By differentiating Eq. (4.12) 2 and then using Eq. (4.12) 1 , we obtain

$$
D \frac{d^{3} \phi}{d x^{3}}=P \frac{d^{2} w}{d x^{2}}
$$


Equation (4.12) $)_{1}$ can be solved for $d \phi / d x$

$$
\frac{d \phi}{d x}=\frac{P-A}{A} \frac{d^{2} w}{d x^{2}}
$$

Substituting Eq. (5.3) into (5.2) and applying the boundary conditions, the buckling load of the Engesser-Timoshenko beam is derived as follows

$$
p_{c r}=\frac{\left(\frac{\pi}{L}\right)^{2} D}{1+\left(\frac{\pi}{L}\right)^{2} \frac{D}{K_{s} A}}
$$

where $K_{s}$ can be expressed as (Lei et al., 2013)

$$
K_{s}=\frac{5}{6-\left(\nu_{1} V_{1}+\nu_{2} V_{2}\right)}
$$

where $\nu_{1}$ and $\nu_{2}$ are Poisson's ratios of the nanoclay and the matrix, respectively, whereas $V_{1}$ and $V_{2}$ are the nanoclay and the matrix volume fractions, respectively. The quantity of $\left(\nu_{1} V_{1}+\nu_{2} V_{2}\right)$ for the presented nanocomposite is infinitesimal, and the shear correction factor can be assumed to $K_{s}=5 / 6$ (Ke et al., 2013).

\section{Results and discussion}

The mechanical buckling of simply supported functionally graded Engesser-Timoshenko nanocomposite beams are studied in this paper. The material compositions of the nanocomposite beams are listed in Table 1 and the material properties are listed in Table 2. The effect of nanoparticles with different weight fractions on the theoretical buckling load are shown in Fig. 5. It is noticed that the buckling loads for the Engesser-Timoshenko beams with uniform distribution of the nanocomposite are genarally lower than the corresponding values for the beams with functionally graded distribution of the nanocomposite. Also, it is seen that the buckling loads for the Engesser-Timoshenko beams with the uniform distribution of nanoparticles increase by increasing the nanoparticles weight percent up to $5 \mathrm{wt} . \%$. By increasing the amount of nanoclay more than $5 \mathrm{wt} . \%$, the buckling load is found to decrease.

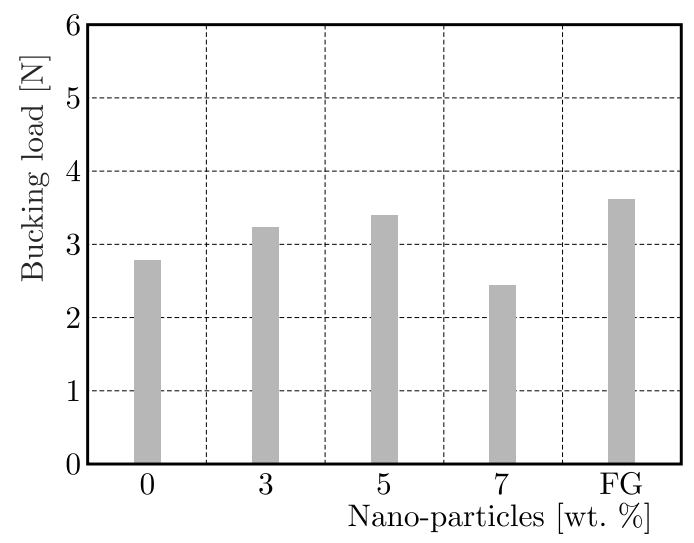

Fig. 5. The effect of nanoparticles with different weight fractions on the buckling load

The comparison between the theoretical and experimental data of the buckling load for uniform by distributed and functionally graded nanocomposites is shown in Table 3. As observed, there is good agreement between the results. Thus the presented approach to analysis of mechanical buckling of uniformly distributed and functionally graded nanocomposites has high accuracy. 
Table 3. Compression between the theoretical and experimental data of the buckling load

\begin{tabular}{|c|c|c|}
\hline $\begin{array}{c}\text { Nanoclay } \\
\text { weight } \\
\text { percent }\end{array}$ & $\begin{array}{c}\text { Theoretical } \\
\text { buckling } \\
\text { load [N] }\end{array}$ & $\begin{array}{c}\text { Experimental } \\
\text { buckling } \\
\text { load [N] }\end{array}$ \\
\hline \hline pure & 2.76 & 2.9 \\
\hline $3 \%$ & 3.19 & 3.3 \\
\hline $5 \%$ & 3.36 & 3.6 \\
\hline $7 \%$ & 2.43 & 2.7 \\
\hline FG & 3.55 & 3.9 \\
\hline
\end{tabular}

\section{Conclusions}

Mechanical buckling of polyethylene/clay nanocomposite columns with uniform and functionally graded distributions of nanoclay based on the Engesser-Timoshenko beam theory is studied. Some conclusions can be drawn as follows:

- The elastic modulus for the FG distribution of nanoclay is generally larger than the corresponding value for the uniform distribution of nanoclay.

- By increasing the nanoparticles weight fractions, the mechanical properties increase up to $5 \mathrm{wt} . \%$ of nanoclay. By increasing the amount of nanoclay more than $5 \mathrm{wt} . \%$, the mechanical properties are found to decrease.

- GA is an acceptable optimization research technique which can be used with confidence to identify mechanical properties of nanocomposites with maximum accuracy.

- The buckling load of the uniformly distributed Engesser-Timoshenko nanocomposite beam is generally lower than the corresponding value for the functionally graded distribution.

- The buckling load of uniformly distributed nanoparticles of the Engesser-Timoshenko beam increases by increasing the nanoparticles weight percent up to $5 \mathrm{wt} \%$ and then, for the amount of nanoclay more than 5 wt.\%, the buckling load is found to decrease.

\section{References}

1. Arani A., Maghamikia S., Mohammadimehr M., Arefmanesh A., 2011, Buckling analysis of laminated composite rectangular plates reinforced by SWCNTs using analytical and finite element methods, Journal of Mechanical Science and Technology, 25, 809-820

2. Barati F., Farahani H., Nezamabadi A., Veiskarami M., 2014, Buckling analysis of functionally graded beams with imperfectly integrated surface piezoelectric layers under low velocity, International Journal of Advances in Applied Mathematics and Mechanics, 2, 64-73

3. Brown D., Mele P., Marceau S., Alberola N.D., 2003, A molecular dynamics study of a model nanoparticle embedded in a polymer matrix, Macromolecules, 36, 1395-1406

4. Eltaher M.A., Emam S.A., Mahmoud F.F., 2013, Static and stability analysis of nonlocal functionally graded nanobeams, Composite Structures, 96, 82-88

5. Fornes T.D., PAUL D.R., 2003, Modeling properties of nylon 6/clay nanocomposites using composite theories, Polymer, 44, 4993-5013

6. Ghiasian S.E., Kiani Y., Eslami M.R., 2015, Nonlinear thermal dynamic buckling of FGM beams, European Journal of Mechanics - A/Solids, 54, 232-242

7. Grigoriadi K., Giannakas A., Ladavos A., Barkoula N.M., 2012, Thermomechanical behavior of polymer/layered silicate clay nanocomposites based on unmodified low density polyethylene, Polymer Engineering Science, 53, 301-308 
8. HeydARI A., 2011, Buckling of functionally graded beams with rectangular and annular sections subjected to axial compression, International Journal Advanced Design and Manufacturing Technology, 5, 25-31

9. Holland J.H., 1975, Adaptation in Natural and Artificial Systems, University of Michigan Press, Ann Arbor, Michigan, U.S.A.

10. Houni M.S.A., Bousalha A.A., Bessaim A., Adda Bedia E.A., Tounsi A., 2013, Buckling of functionally graded nanobeams based on the nonlocal new first-order shear deformation beam theory, International Congress on Materials and Structural Stability, 427-428

11. Jia W.L., Zhao L., Hou L., Ji W.L., Shi W., Qu G. H., 2014, Theoretical analysis of carbon nanotube photomixer-generated terahertz power, Acta Physica Sinica, 63, 72-77

12. Ke L.L., YAng J., Kitipornchai S., 2013, Dynamic stability of functionally graded carbon nanotube-reinforced composite beams, Mechanics of Advanced Materials and Structures, 20, 28-37

13. Kiani Y., Eslami M.R., 2010, Thermal buckling analysis of functionally graded material beams, International Journal of Mechanics and Materials in Design, 6, 229-238

14. Kiani Y., Eslami M.R., 2013, Thermomechanical buckling of temperature-dependent FGM beams, Latin American Journal of Solids and Structures, 10, 223-245

15. Kozlov G., Dzhangurazov B., Ziakov G., Mikitaev A., 2012, The nanocomposites polyethylene/organoclay permeability to gas description within the frameworks of percolation and multifractal models, Chemistry and Chemical Technology, 6, 163-166

16. LEI Z.X., LiEw K.M., YU J.L., 2013a, Buckling analysis of functionally graded carbon nanotube-reinforced composite plates using the element - kp-Ritz method, Composite Structures, 98, 160-168

17. LEI Z.X., LIEW K.M., YU J.L., 2013b, Free vibration analysis of functionally graded carbon nanotube-reinforced composite plates using the element-kp-Ritz method in thermal environment, Composite Structures, 106, 128-138

18. Lei D., Menggen Q. Q. G., Zhang H. L., Zhi Y. B., 2013c, Field emission properties from a carbon nanotube array with parallel grid, Acta Physica Sinica, 62, 48-50

19. Li S., WANG X., WAN Z., 2015, Classical and homogenized expressions for buckling solutions of functionally graded material Levinson beams, Acta Mechanica Solida Sinica, 28, 592-604

20. Majumdar A., Das D., 2016, A study on thermal buckling load of clamped functionally graded beams under linear and nonlinear thermal gradient across thickness, Proceedings of the Institution of Mechanical Engineers, Part L: Journal of Materials: Design and Applications, 1, 23-32

21. Mosallaie Barzoki A.A., Ghorbanpour Arani A., Kolahchi A., Mozdianfard M.R., 2012, Electro-thermo-mechanical torsional buckling of a piezoelectric polymeric cylindrical shell reinforced by DWBNNTs with an elastic core, Applied Mathematical Modelling, 36, 2983-2995

22. Nam P.H., Maiti P., Okamoto M., 2001, Hierarchical structure and properties of intercalated polypropylene/clay nanocomposite, Polymer, 42, 9633-9640

23. Pakdaman A.S., Morshedian J., Jahani Y., 2013, Effect of organoclay and silane grafting of polyethylene on morphology, barrierity, and rheological properties of HDPE/PA6 blends, Journal of Applied Polymer Science, 127, 1211-1220

24. Rafiee M.A., Rafiee J., Yu Z.Z., Koratkar N., 2009, Buckling resistant graphene nanocomposites, Applied Physics Letters, 95, 223103

25. REDDy J.N., 2004, Mechanics of Laminated Composite Plates and Shells Theory and Analysis, CRC, New York, U.S.A.

26. RychlewskA J., 2014, Buckling analysis of axially functionally graded beams, Journal of Applied Mathematics and Computional Mechanics, 13, 103-108

27. SHEN H.S., 2011a, Postbuckling of nanotube-reinforced composite cylindrical shells in thermal environments. Part I: Axially-loaded shells, Composite Structures, 93, 2096-2108 
28. Shen H.S., 2011b, Postbuckling of nanotube-reinforced composite cylindrical shells in thermal environments. Part II: Pressure-loaded shells, Composite Structures, 93, 2496-2503

29. Sheng N., Boyce M.C., PArks D.M., 2004, Multiscale micromechanical modeling of polymer/clay nanocomposites and the effective clay particle, Polymer, 45, 487-506

30. Simsek M., Yurtsu H.H., 2013, Analytical solutions for bending and buckling of functionally graded nanobeams based on the nonlocal Timoshenko beam theory, Composite Structures, 97, 378-386

31. Smith G.D., Bedrov D., Li L., Byutner O.A., 2002, A molecular dynamics simulation study of the viscoelastic properties of polymer nanocomposites, Journal of Chemical Physics, 20, 9478-9489

32. Sun Y., Li S.R., BAtra R.C., 2016, Thermal buckling and post-buckling of FGM Timoshenko beams on nonlinear elastic foundation, Journal of Thermal Stresses, 39, 11-26

33. Thomas B., Inamdar P., Roy, T., Nada B.K., 2013, Finite element modeling and free vibration analysis of functionally graded nanocomposite beams reinforced by randomly oriented carbon nanotubes, International Journal on Theoretical and Applied Research in Mechanical Engineering, 2, 97-102

34. Vodenitcharova T., Zhang L.C., 2006, Bending and local buckling of a nanocomposite beam reinforced by a single-walled carbon nanotube, International Journal of Solids and Structures, 43, 3006-3024

35. Wang C.M., Reddy J.N., 2000, Shear Deformable Beams and Plates, Elsevier, Oxford, England

36. Yin G.H., Deng Q.T., YANG Z.C., 2015, Bending and buckling of functionally graded Poisson's ratio nanoscale beam based on nonlocal theory, Iranian Journal of Science and Technology, 39, 559-565

Manuscript received March 1, 2017; accepted for print November 5, 2017 